\title{
A Lacuna Jurídica em Relação ao Ato Infracional Análogo ao Crime de Estupro de Vulnerável e a Possibilidade de Relativização da Vulnerabilidade da Vítima’
}

\author{
Denisson Gonçalves Chaves ${ }^{2}$ \\ Mágila Martins Furtado 3
}

\section{RESUMO}

presente trabalho analisa a adequabilidade dos entendimentos normativos, doutrinários e jurisprudenciais a respeito da vulnerabilidade da vítima nos casos de ato infracional análogo ao crime de estupro de vulnerável quando o ato sexual for cometido entre adolescentes de forma consentida. Para tanto, utilizou-se o método qualitativo, tendo em vista que se trata de um estudo exploratório feito através de profunda pesquisa bibliográfica. Constatou-se que há uma lacuna jurídica em relação ao ato infracional análogo ao crime de estupro de vulnerável que exige dos operadores do direito uma análise específica dos casos envolvendo o relacionamento sexual consentido entre adolescentes. Como solução para a lacuna jurídica defende-se que seja adotada no Brasil uma cláusula semelhante à exceção de Romeu e Julieta, utilizada em alguns estados dos Estados Unidos da América para descriminalizar o relacionamento sexual

1Data de recebimento: 18/06/2018. Data de aceite: 21/09/2018.

2 Mestre em Direito e Instituições do Sistema de Justiça (UFMA); Bacharel em Direito pela Universidade Federal do Maranhão (UFMA); Professor na Universidade Federal do Maranhão (UFMA); Professor na Unidade de Ensino Superior do Sul do Maranhão (UNISULMA); Professor na Faculdade de Imperatriz - FACIMP WYDEN; Pesquisador no Grupo de Pesquisa Cultura, Direito e Sociedade; Coordenador do Núcleo de Pesquisas Jurídicas de Imperatriz - Democracia e Direitos Fundamentais (NUPEJI). E-mail: denissongoncalves@gmail.com

3 Graduada em Direito pela Universidade Federal do Maranhão (UFMA). Advogada na seccional do Maranhão. E-mail: denissongoncalves@gmail.com 
entre adolescentes quando a idade entre eles for igual ou inferior a cinco anos.

Palavras-Chave: Estupro de vulnerável. Ato infracional. Vulnerabilidade. Lacuna jurídica. Exceção de Romeu e Julieta.

\section{INTRODUÇÃO}

Em 7 de agosto de 2009 o código penal brasileiro (CPB) sofreu uma grande reforma com o advento da Lei $n^{\circ} 12.015$, dentre os artigos modificados estava o art. 224, o qual previa hipóteses em que os crimes sexuais seriam presumidos. Contudo, a palavra presunção gerava muitas discussões sobre a sua natureza quando a vítima fosse menor de 14 anos, se esta seria absoluta ou relativa. Neste sentido, buscando pacificar a questão o legislador optou por criar o tipo autônomo intitulado de: estupro de vulnerável, tipificado no art. 217-A do código.

Tal alteração, para muitos, veio para pacificar a questão da vulnerabilidade da vítima, contudo, ainda hoje é possível ver entendimentos doutrinários e decisões judiciais contrárias a essa presunção absoluta. Ocorre que recentemente o Superior Tribunal de Justiça estabeleceu na enunciado de súmula 593, que deve ser desconsiderada qualquer análise subjetiva sobre o crime, diante disso, dificilmente ainda haverá decisões no sentido de considerar a vulnerabilidade da vítima como relativa.

O presente trabalho visa analisar os reflexos dessa súmula e dos demais entendimentos sobre a vulnerabilidade da vítima em relação ao ato sexual consentido praticado entre adolescentes, quando um deles ou ambos forem menores de 14 anos. Pois, considerando-se a vulnerabilidade como absoluta poderiam ambos os adolescentes serem punidos criminalmente. A partir disso, surge o seguinte questionamento:

É adequada a presunção absoluta de vulnerabilidade da vítima no 
ato infracional análogo ao crime de estrupo de vulnerável quando ambos os sujeitos forem adolescentes (maiores de 12 anos) e o ato sexual ocorra de forma consentida?

Diante disso, o trabalho tem como objetivo analisar a adequabilidade normativa, doutrinária e jurisprudencial a respeito da presunção absoluta de vulnerabilidade da vítima nos crimes de estupro de vulnerável quando cometido por adolescentes de forma consentida.

O tema se mostra atual em razão da súmula recentemente editada pelo STJ, pois demonstra a necessidade de uma maior reflexão sobre o tema quando o ato sexual ocorrer entre adolescentes com idades próximas de forma consentida, de modo que não haja a criminalização desmedida.

Utiliza-se neste trabalho o método qualitativo, tendo em vista que não há a consideração de dados estatísticos, tratando-se de um estudo exploratório feito através de profunda pesquisa bibliográfica, em que foram analisados aspectos legais, doutrinários e jurisprudenciais acerca do tema, cujo escopo é analisar a vulnerabilidade da vítima quando o ato sexual é cometido de forma consentida entre adolescentes, e um deles ou os dois envolvidos sejam menores de 14 anos, considerando se o entendimento normativo, doutrinário e jurisprudencial é adequado para solucionar esses casos. Além disso, pretende-se identificar a lacuna jurídica em relação ao ato infracional análogo ao crime de estupro de vulnerável e apresentar uma proposta para solucioná-la.

\section{CONSIDERAÇÕES SOBRE O ESTUPRO DE VULNERÁVEL: A ATUAL CONVERGÊNCIA LEGAL E JURISPRUDENCIAL}

O crime de estupro de vulnerável está tipificado, atualmente, no art. 217-A do Código Penal Brasileiro, e dispõe que:

\section{Estupro de vulnerável}

Art. 217-A. Ter conjunção carnal ou praticar outro ato 
libidinoso com menor de 14 (catorze) anos:

Pena - reclusão, de 8 (oito) a 15 (quinze) anos.

$\S 1$ Incorre na mesma pena quem pratica as ações descritas no caput com alguém que, por enfermidade ou deficiência mental, não tem o necessário discernimento para a prática do ato, ou que, por qualquer outra causa, não pode oferecer resistência.

[...]

§ 3 ㅇ Se da conduta resulta lesão corporal de natureza grave:

Pena - reclusão, de 10 (dez) a 20 (vinte) anos.

$\S 4^{\circ}$ Se da conduta resulta morte:

Pena - reclusão, de 12 (doze) a 30 (trinta) anos.

O referido artigo foi inserido no CPB com a edição da lei $n^{\circ}$. 12.015/2009 que teve como objetivo proteger crianças e adolescentes de abusos sexuais. É certo que no mundo globalizado os criminosos sexuais se valem de inúmeros artifícios para praticarem ato sexual com menores de idade. Neste contexto, o legislador adotou o critério etário para determinar a vulnerabilidade4 desses indivíduos e assim evitar que eles fossem coagidos a ter relações sexuais, considerando-os incapazes até mesmo de consentirem com o ato.

Além do critério etário, o legislador também considerou como vulnerável aquele que possui alguma deficiência física ou mental que o impeça de ter o necessário discernimento para a prática do ato, e aquele que, por qualquer outra causa, não poder oferecer o consentimento válido, conforme redação acima transcrita.

Por sua vez, o debate acerca da natureza jurídica da vulnerabilidade prevista no crime de estupro de vulnerável também se estendeu ao âmbito dos tribunais. São inúmeros os julgados sobre o tema. Contundo, em 2017, o Superior Tribunal de Justiça editou a súmula n 539, nos seguintes termos:

Súmula 593 - O crime de estupro de vulnerável se configura com a conjunção carnal ou prática de ato libidinoso

4 Vulnerável, segundo Capez (2012, pg. 103): é qualquer pessoa em situação de fragilidade ou perigo. A lei não se refere aqui à capacidade para consentir ou à maturidade sexual da vítima, mas ao fato de se encontrar em situação de maior fraqueza moral, social, cultural, fisiológica, biológica etc. 
com menor de 14 anos, sendo irrelevante eventual consentimento da vítima para a prática do ato, sua experiência sexual anterior ou existência de relacionamento amoroso com o agente (BRASIL, 2017).

A súmula veio para pacificar de vez as divergências relacionadas ao crime de estupro de vulnerável. Isto porque as súmulas são o resultado da jurisprudência dominante nos tribunais superiores e servem para proporcionar maior estabilidade jurídica e simplificar o julgamento das questões que são mais submetidas ao Judiciário (STRECK apud PINHEIRO, 2007).

Como visto, o art. 217-A do código penal, ratificado pela Súmula $n^{\circ} 593$ do STJ, criminaliza todo ato sexual praticado com menores de quatorze anos. Segundo o entendimento minoritário da doutrina e do posicionamento pacífico da jurisprudência5, trata-se de tipo objetivo, sendo irrelevante se houve violência ou o consentimento da vítima para a prática do ato.

Nesse sentido, questiona-se, e se o ato sexual ocorresse entre adolescentes em idade próxima, dentro de um relacionamento amoroso reconhecido pelos pais, ainda assim, a conduta deveria ser criminalizada? E se for entre dois adolescentes menores de quatorze anos, ambos serão punidos?

Sendo o tipo penal de natureza absoluta, a resposta só pode ser positiva, vez que não se admite a análise das particularidades do caso concreto. Assim, aplicando-se literalmente o ECA, os adolescentes responderiam por ato infracional análogo ao crime de estupro de vulnerável.

Pela análise feita sobre a vulnerabilidade da vítima percebe-se que os julgadores e os doutrinadores ao defenderem a presunção absoluta analisaram o tema a partir da perspectiva da violação sexual de crianças e adolescentes por adultos. Entretanto, poucos são

5 Nesse ponto, percebe-se uma clara distinção entre o posicionamento jurisprudencial e doutrinário. De acordo com este último, a análise da vulnerabilidade dar-se caso a caso. Enquanto a jurisprudência tende por uma perspectiva geral e absoluta da vulnerabilidade. 
os debates relativos ao ato sexual praticado entre adolescentes de forma consentida.

Nesse sentido, Aleixo (2010, apud NUCCI, 2014) defende que a aplicação do dispositivo penal refuta maior reflexão quando aplicado contra atos de adolescentes, em razão da sua condição de pessoa em desenvolvimento, sob pena de criminalizar a natural experiência sexual, proibindo a autoderminação dos menores de 14 anos.

Inicialmente, é necessário reconhecer que há diferença entre o ato sexual realizado de forma consentida entre adolescentes e o sexo entre estes e o adulto. Viu-se que o legislador institui-o a figura do vulnerável para pacificar a dicotomia entre a presunção prevista no revogado art. 224 do CPB. Contudo, como demostrado, a doutrina e a jurisprudência nunca se afinaram unicamente em um posicionamento.

Sendo que agora a discussão permanecia sobre a figura da vulnerabilidade (NUCCI, 2009). Sobre isso, Budó (2015, p. 1052) declara que: "A vulnerabilidade não existe ontologicamente, ela existe em relação a algo. Crianças e adolescentes podem ser vulneráveis, por exemplo, aos adultos, ou mesmo ao sistema de controle penal".

Diante do disso, defende-se que a vulnerabilidade prevista pelo legislador no tipo penal em estudo refere-se à relação destes com os adultos. É o que se infere dos fundamentos utilizados para defender a presunção absoluta.

Greco (2015), por exemplo, pontua que o tipo penal objetivo se justifica em razão do mundo globalizado está cada vez mais sujeito a atuação de pedófilos que se valem de inúmeros artifícios para seduzir suas vítimas. Nesse mesmo sentido, consistem os fundamentos utilizados pelos juízes na defesa da reprimenda penal de natureza objetiva, senão vejamos:

Não é por outra razão que a regra do art. 224, 'a' do CP era vista como uma norma cujo conteúdo estabelece antes de tudo um dever geral de abstenção (HC 73.662 voto vencido Néri) a dizer que não devem e não podem os 
adultos aproveitarem-se da menoridade das vítimas para exercício de seus propósitos sexuais (Recurso especial $\mathrm{n}^{\circ}$ 1.021.634 - SP, voto: Min. Dilson Dipp, Dje: 27/06/2014).

O exame da história das ideias penais - e, em particular, das opções de política criminal que deram ensejo às sucessivas normatizações do Direito Penal brasileiro - demonstra que não mais se tolera a provocada e precoce iniciação sexual de crianças e adolescentes por adultos que se valem da imaturidade da pessoa ainda em formação física e psíquica para satisfazer seus desejos sexuais (Recurso Especial $\mathrm{n}$. 1.480.881/PI, Rel. Rogério Schietti Cruz, Dje: 10/09/2015).

Portanto, o parâmetro da vulnerabilidade não pode ser aplicado em todos os casos, tendo em vista que só irá existir em relação a algo ou alguém, e no caso previsto em lei, considera-se o menor de quatorze anos vulnerável ao adulto. Diante disso, nas relações sexuais envolvendo adolescentes não há que se falar em vulnerabilidade quando o ato ocorrer de forma consentida.

Isto porque os jovens estão, muitas vezes, em situação de proximidade de grau de desenvolvimento físico, emocional e psíquico, que exige dos operadores do direito uma maior habilidade na condução do caso (SARAIVA, 2009). Ademais, a desconsideração destes aspectos pode ocasionar a criminalização do ato sexual entre adolescentes e causar danos irreversíveis na vida daquele que estará sujeito ao sistema penal juvenil.

Diante do exposto, verifica-se a necessidade de uma análise específica pelos legisladores, doutrinadores e julgadores em relação aos casos envolvendo adolescentes. Entende-se que não seria justa a utilização de uma mesma regra para adultos e adolescentes, sem que ao menos pudessem ser analisadas as particularidades relativas a estes últimos, as quais serão analisadas nos próximos tópicos.

\section{CONTEXTUALIZANDO COM O ATO INFRACIONAL}

Segundo o art. 103 do Estatuto da Criança e do Adolescente 
"considera-se ato infracional a conduta descrita como crime ou contravenção penal" (BRASIL, 1990). Portanto, ato infracional é toda ação violadora dos tipos penais quando praticada por menores de dezoito anos.

Segundo Sposato (2013) adotou-se no Brasil a tipificação delegada, a qual consiste na aplicação dos mesmos tipos penais de adultos para definir as infrações do sistema de justiça juvenil. Desta forma, para configuração do ato infracional são necessários os mesmos requisitos do crime, ou seja, o ato deve ser típico, antijurídico e culpável.

Todavia, considerando o estado peculiar das crianças e dos adolescentes como pessoas em desenvolvimento, o legislador optou pela impossibilidade deles praticarem crimes, definindo-os como penalmente inimputáveis. A respeito disso, esclarece Barros:

\begin{abstract}
Considerando que a imputabilidade compõe o elemento 'culpa', conclui-se, portanto, que adolescentes não cometem crime e sim conduta análoga, chamada de ato infracional, comportando medidas diversas daquelas dadas ao crime ou contravenção (2013, apud CORREA, 2016, p. 22).
\end{abstract}

Pode-se dizer que a inimputabilidade penal é um avanço na política criminal brasileira, pois, apesar da polêmica a respeito do tema, há de se considerar que os adolescentes são mais propensos a mudarem seu comportamento do que os adultos. Sobre o assunto, Moraes e Ramos (2014) defendem que os adolescentes devem ter um sistema compatível com o seu grau de responsabilização, devendo-lhes ser aplicada medida de caráter pedagógico, tendo em vista que o sujeito de dezoito anos ainda é passível de ser educado.

Além de diferi-los dos adultos, o ECA ainda diferencia o tratamento dado às crianças e aos adolescentes. Segundo o disposto no art. $2^{\circ}$ do diploma legal, considera-se criança a pessoa até doze anos de idade incompletos e adolescentes aqueles que possuem entre doze e dezoito anos de idade. Em se tratando de ato infracional praticado 
por crianças aplica-se medidas de proteção, caso seja um adolescente, este ficará sujeito às medidas socioeducativas6 (BRASIL, 1990).

Trata-se de rol não taxativo, podendo o julgador aplica-las isolada ou cumulativamente, da forma que melhor atenda às necessidades do caso concreto. Além disso, insta mencionar, que o estatuto não estabeleceu procedimentos específicos em relação à apuração e julgamento do ato infracional praticado por crianças, somente determinou a competência do Conselho tutelar para aplicação das medidas (BRASIL, 1990).

Por outro lado, a persecução penal do ECA em relação aos adolescentes se assemelha em muitos aspectos ao processo penal dos adultos. Na apuração do ato infracional, ao contrário das medidas de proteção aplicadas às crianças, há três fases distintas, sendo a primeira a investigação policial, na qual há a apuração dos fatos e colhimento de depoimentos nos moldes previstos no Código de Processo Penal.

Após essa fase, tem-se início a atuação do Ministério Público. Cabe, inicialmente, esclarecer que todos os atos infracionais são de ação pública incondicionada, desta forma, o parquet sempre será o titular da ação contra adolescentes. No entanto, embora pareça ser um contrassenso o maior rigor em relação ao sistema dos adultos, a imposição da exclusiva atribuição ministerial, encontra respaldo na possibilidade do membro do parquet fazer um maior juízo de valor acerca da propositura da representação (MORAES; RAMOS, 2014).

Ao contrário da seara criminal, que é regida pelo princípio da indisponibilidade, na área da infância e juventude é possível que o

\footnotetext{
6 As medidas de proteção a serem aplicadas as crianças são as previstas no art. 101 do ECA: Art. 101. Verificada qualquer das hipóteses previstas no art. 98, a autoridade competente poderá determinar, dentre outras, as seguintes medidas: I - encaminhamento aos pais ou responsável, mediante termo de responsabilidade; II - orientação, apoio e acompanhamento temporários; III - matrícula e frequência obrigatórias em estabelecimento oficial de ensino fundamental; IV - inclusão em serviços e programas oficiais ou comunitários de proteção, apoio e promoção da família, da criança e do adolescente; $\mathrm{V}$ requisição de tratamento médico, psicológico ou psiquiátrico, em regime hospitalar ou ambulatorial; VI - inclusão em programa oficial ou comunitário de auxílio, orientação e tratamento a alcoólatras e toxicômanos; VII - acolhimento institucional; VIII - inclusão em programa de acolhimento familiar; IX - colocação em família substituta.
} 
Ministério Público após a oitiva prévia do adolescente, possa pedir o arquivamento da ação ou aplicar-lhe a remissão. Desta forma, tem o promotor de justiça a faculdade de escolher a melhor opção para efetivar a ressocialização do menor.

Já em caso de representação pelo ato infracional, tem-se início a terceira fase que é a judicial. Nesta o juiz poderá condenar o adolescente nas medidas socioeducativas previstas no rol taxativo do art. 112 do ECA7 (BRASIL, 1990).

As medidas socioeducativas serão aplicadas de acordo com a infração cometida, cabendo ao juiz o dever de analisar a capacidade do adolescente em cumprir a medida, bem como as circunstâncias e a gravidade do ato infracional, de modo que se possa aferir a adequação e a proporcionalidade da reprimenda estatal (FULLER; DEZEM; JÚNIOR, 2012). Desse modo, além da punição, a medida aplicada deve ser aquela que seja mais eficaz na reeducação do infrator.

Fica claro que os jovens apesar de receberem sanções diferentes das aplicadas aos adultos, em razão de sua condição de ser em desenvolvimento, não deixam de ser responsabilizados pela sua conduta. Longe disso, a eles são aplicadas medidas que são verdadeiras sanções jurídico-penais, vez que se assemelham em muitos aspectos as penas tradicionais, resultando, inclusive, em privação de liberdade, como no caso da internação (SPOSATO, 2013).

Desta forma, impõe-se a incidência restrita e limitada das medidas socioeducativas aos casos de extrema necessidade. De modo que se impeça qualquer prejuízo ao desenvolvimento e formação da criança e do adolescente que estão sobre o manto da proteção estatal, comunitária e familiar.

\section{UMA POSSÍVEL SAÍDA: EXCEÇÃO DE ROMEU E JULIETA}

7 In verbis: Art. 112. Verificada a prática de ato infracional, a autoridade competente poderá aplicar ao adolescente as seguintes medidas: I - advertência; II - obrigação de reparar o dano; III - prestação de serviços à comunidade; IV - liberdade assistida; V - inserção em regime de semi-liberdade; VI - internação em estabelecimento educacional; VII - qualquer uma das previstas no art. 101, I a VI. 
A definição de uma idade mínima para a validade do consentimento sexual é importante para proteger crianças e adolescentes do abuso e da exploração sexual, bem como das consequências que possam resultar de um ato prematuro, como a gravidez ou transmissão de doenças sexuais. Contudo, a manutenção da idade de 14 anos como limite objetivo não pode continuar a ser utilizada como mesmo parâmetro para as relações entre o adulto e o adolescente e entre adolescentes em idade próxima.

Nesse sentido, alguns estados8 dos Estados Unidos da América, que costumam punir rigorosamente os crimes sexuais, criaram a chamada Romeo and Juliet Law, que pode ser traduzida para o português como "exceção de Romeu e Julieta". A lei consiste em não reconhecer a presunção de violência quando a diferença de idade entre os personagens seja igual ou inferior a cinco anos. Com isso, busca-se evitar a punição da descoberta sexual (SARAIVA, 2009).

A norma norte-americana em comento surgiu em 2007, e foi inspirada na obra Romeu e Julieta de Willian Shakespeare. A história narra o romance entre dois jovens, os quais se presumem, que possuíam a idade de dezesseis anos e treze anos, respectivamente. Assim, caso o romance ocorresse no Brasil, Romeu seria considerado estuprador nos termos do art. 217-A do CPB.

Sobre o assunto João Batista Costa Saraiva (2009, p. 63), declara que:

(...) exagera a norma ao fixar em 14 e não em 12 anos a idade limite, ao menos sem estabelecer uma regra como a "Exceção de Romeu e Julieta".

Em matéria de relacionamento sexual entre adolescentes, a nova regra do art. 217 exagera em face da realidade do País e de nossa adolescência, podendo criminalizar a conduta de muitos adolescentes e pré-adolescentes na descoberta de sua sexualidade.

8 Exemplos de estados norte-americanos que adotam a Romeo and Juliet law: Connecticut, Flórida, Indiana, Texas, Hawaii, Alabama, Colorado, New Jersey, New Mexico, entre outros. Fonte: Legal dictionary. Disponível em: <https://legaldictionary.net/romeo-and-juliet-laws/>. Acesso em: 18/11/2017. 
O autor defende, ainda, que a norma penal deveria acompanhar a idade estabelecida no ECA para diferenciar crianças e adolescentes, tendo em vista que a estes últimos a lei considera diversas prerrogativas, como viajar desacompanhado, ser privado de sua liberdade, direito de ser ouvido, entre outras. Contudo, afirma que caso permaneça a limitação etária em 14 anos, deveria ser criada uma regra de exceção como a Romeu and Juliet law. Frisa-se que a referida cláusula só seria aplicada aos jovens maiores de 12 anos, tendo em vista que não há possibilidade de relativização, em razão do próprio limite previsto pelo ECA.

Entretanto, observa-se, que a manutenção da natureza absoluta da presunção de violência pode levar ao juizado da infância e juventude adolescentes que estão descobrindo a sua sexualidade, e que não poderiam ser penalizados criminalmente por tal ato. Pois, a condução equivocada dessa situação pode ocasionar prejuízos irreversíveis na vida dos adolescentes envolvidos (SILVA, 2014).

Com efeito, a aplicação da exceção de Romeu e Julieta visa a corrigir as injustiças legais que ao invés de proteger os adolescentes terminam por criminaliza-las. Sobre isto, insta destacar um julgado norte-americano paradigma que revelou as injustiças que podem surgir a partir da consideração estrita da lei e a importância da criação de uma regra de exceção.

Trata-se do caso do jovem Garnalow Wilson, de 17 anos de idade, condenado pelo Estado da Georgia (cuja legislação proíbe o sexo entre adolescentes) a 15 anos de prisão por ter praticado sexo oral com uma menina de quinze anos de idade. No julgamento restou claro para todos que o ato havia sido consentido e que não houve qualquer abuso por parte do garoto, inclusive havia imagens que mostravam claramente o ocorrido. Contudo, mesmo diante dos fatos ele foi condenado e somente foi liberado em 9 de junho de 2007, após cumprir dois anos na prisão, por decisão da Suprema Corte do 
Estado da Geórgia que aplicou a exceção de Romeu e Julieta ao caso.9

No Brasil, alguns tribunais estaduais também vêm aplicando a teoria para solucionar questões envolvendo o relacionamento sexual entre pessoas de idade próxima. Por exemplo, cita-se o Tribunal de Justiça de Goiás que entendeu que a conduta dos jovens deveria ser relativizada em razão da proximidade etária, bem como reconheceu a liberdade dos adolescentes em consentir com o ato.

\begin{abstract}
APELAÇÃO CRIMINAL. ESTUPRO DE VULNERÁVEL. DIREITO COMPARADO. ANÁLISE DO CASO CONCRETO. EXCEÇÃO ROMEU E JULIETA (ROMEO AND JULIET LAW). ABSOLVIÇÃO.

$\mathrm{Na}$ esteira do direito comparado, o direito brasileiro deve adotar orientação semelhante, de que não existe crime para os casos em que não for constatada a exploração sexual dos adolescentes e tratar-se a hipótese de atos sexuais cometidos entre adolescentes/jovens, com idades próximas, de livre e espontânea vontade, sem resultar em mudança comportamental ou abalo psicológico (art. 386, inciso VI, Código Processual Penal) ${ }^{10}$.
\end{abstract}

Assim também seguiu o Tribunal de Justiça de Santa Catarina, no julgamento da apelação: 20110983973 , que tratava de relacionamento sexual entre primos, com idades de 13 e 15 anos. No qual o relator desembargador Ricardo Roesler, considerando a exceção de Romeu e Julieta, votou pela absolvição do representado.

A violência ficta contra menor de 14 anos, que alicerça o crime de estupro de vulnerável (art. 217-A, do CP), pressupõe a incapacidade de plena autodeterminação e de defesa do menor, em contrapartida à previsível maturidade do adulto. Bem por isso, tratando-se de prática sexual entre adolescentes - uma com 13 anos (vítima) e outro com 15 anos (autor) - não incide livrevemente a presunção para caracterizar o fato como ato infracional análogo ao crime

\footnotetext{
9 TUCK, Angela. Genarlow Wilson's journey from prison to Morehouse. Atlanta Journal Constitution. Atlanta, 18/05/2013. Disponivel em: < http://www.myajc.com/news/crime--law/genarlow-wilson-journey-from-prison-morehouse/BSmOzTV5gU4sjRvAgsuEBM/>. Acesso em: 02/02/2018.

10 APELO CONHECIDO E PROVIDO. SENTENÇA REFORMADA. (TJ-GO - APR: 03471174020138090095, Relator: DES. Leandro Crispim, data de julgamento: 02/05/2017, 2A Camara Criminal, data de publicação: DJ 2316 de 27/07/2017.
} 
de estupro; é necessário que se evidencie que o adolescente tinha exata compreensão das circunstâncias e, principalmente, o intuito deliberado de satisfazer a própria lascívia, contando com a prematuridade e a inexperiência da vítima. (...) Bem porque a presunção de violência é tomada a partir da suposição de experiência de um (o adulto) e da imaturidade do outro (a vítima); a mesma conclusão não pode ser simplesmente tomada quando em jogo a prática de ato sexual entre dois menores (grifo nosso). (...) Se não somos capazes de admitir a nós mesmos nossas limitações, que tenhamos apenas alguma sensibilidade com a alma humana, e tomemos como paradigma o exemplo hoje adotado nos Estados Unidos - país notoriamente reconhecido pela repreensão a crimes sexuais cometidos por jovens (notadamente os homossexuais), mas que tem admitido a atipicidade da conduta quando a relação sexual ocorre entre adolescentes. É o que se convencionou chamar Romeo and Juliet Law . O dispositivo, de inspiração shakespereana, tem se firmado como forma de impedir o apenamento de jovens que mantenham relações sexuais, cuja diferença de idade não ultrapasse cinco anos. (...)O direito, sobretudo o direito penal há de se ocupar necessariamente daquilo que deva ser submetido à sua correção. E para identificar o que é passível de intervenção pelo Judiciário do que não é se exige mais, bem mais do que a burocracia e a arrogância dos protocolos jurídicos: exige-se sensibilidade, atenção com o outro; requer-se alguma ampliação de horizontes da sensibilidade. A solução de todas as misérias humanas não é tarefa do Judiciário, que quando muito tem figuração coadjuvante. Quando os papéis se invertem, quando o Judiciário intervém para além de suas cercanias, sem cuidado e cautela, o resultado pode ser desastroso. Soluções que possam parecer, num olhar desavisado, um sintoma de justiça poética (belíssima nas obras literárias, mas de regra patética como pauta de julgamento) podem, na prática, desdobrar efeitos colaterais muito mais perniciosos do que a efetiva inércia judicial. Eis um caso cuja alguma solução deve ser buscada longe, muito longe da intervenção direta do Judiciário (Grifado).

As decisões apresentadas mostram a necessidade do aplicador do direito poder em alguns casos excepcionais relativizar a vulnerabilidade da vítima, observando as peculiaridades do caso concreto. Tendo como finalidade evitar decisões desproporcionais.

Nesse sentido, defende-se que a idade mínima para o consenti- 
mento sexual entre adolescentes, leve em consideração a diferença de idade e a possibilidade de equilíbrio de poder para determinar se o consentimento será válido. Sendo assim, é fundamental que enquanto não ocorra uma reforma legal que defina uma exceção nos termos da Romeo and Juliet law, os julgadores possam continuar a analisar o aspecto material para caracterizar o ato infracional.

\section{CONCLUSÃO}

O desenvolvimento do presente estudo possibilitou uma análise de como a legislação, os doutrinadores e os julgadores compreendem a natureza da presunção de vulnerabilidade da vítima no crime de estupro de vulnerável. A partir disso, permitiu-se uma reflexão sobre as dificuldades encontradas para solucionar casos envolvendo o relacionamento sexual consensual entre adolescentes e a importância de uma análise específica sobre o tema.

De um modo geral, os entendimentos acerca da vulnerabilidade da vítima são no sentido de atribuir-lhe a natureza absoluta, ou seja, se houve o fato, há o crime, portanto, entende-se que a lei não permite a verificação de outras circunstâncias presentes no caso concreto. No entanto, verificou-se que o mesmo posicionamento não poderia ser aplicado aos adolescentes que praticam ato sexual consensual, quando um ou ambos forem menores de quatorze anos, sob pena de criminalizar a sua descoberta sexual.

Percebeu-se que na atual sistemática adotada pelo Brasil é possível que adolescentes respondam por ato infracional análogo ao crime de estupro de vulnerável mesmo que vítima e acusado estejam em situação de proximidade etária e grau de desenvolvimento físico, psíquico e emocional. Diante disso, demonstrou-se que há fundamentos que justificam a possibilidade de relativização da vulnerabilidade da vítima nesses casos específicos.

As considerações sobre os aspectos do crime de estupro de 
vulnerável permitiram a compreensão sobre os conceitos e características do tipo em estudo. Viu-se que o legislador adotou o critério etário para determinar a vulnerabilidade da vítima, definindo a idade mínima de 14 anos para que o indivíduo possa consentir com o ato sexual. Além disso, em relação ao bem jurídico protegido pôde-se esclarecer que há diferenças entre o adulto e o adolescente, sendo que ao primeiro considera-se bem mediato a liberdade sexual, e ao último o desenvolvimento sexual, tendo, ambos, como bem imediato a dignidade sexual.

Por ser um crime de extrema gravidade e de alta reprovabilidade social a penalidade atribuída ao tipo é consideravelmente alta, estando o crime previsto no rol dos crimes hediondos. Diante disso, o legislador na reforma do código penal com o advento da lei 12.015/2009, resolveu tratar a vulnerabilidade etária como absoluta, de modo que não houvesse margem para qualquer interpretação que pudesse levar a impunidade do agressor ou mesmo na desqualificação da vítima. Apesar disso, os debates doutrinários não são uníssonos, pois, embora todos reconheçam a escolha do legislador, a maioria dos autores pesquisados, ainda, defende a possibilidade de relativizar a vulnerabilidade da vítima diante das circunstâncias do caso concreto.

Ademais, analisou-se o entendimento dos tribunais acerca da dicotomia em relação à vulnerabilidade: absoluta x relativa. Observou-se que antes da reforma, os tribunais superiores divergiam nos seus entendimentos, enquanto o STF argumentava em favor da presunção absoluta em quase todos os seus julgados, o STJ não tinha assumido uma posição pacífica sobre o assunto. Após a reforma, o STF consolidou de vez o entendimento pela vulnerabilidade absoluta. Por outro lado, no Superior Tribunal de Justiça, permaneciam os debates.

Somente no ano de 2014, o STJ pacificou o seu entendimento, passando a considerar a vulnerabilidade prevista no art. 217-A como de natureza absoluta, sendo que recentemente, firmou sua posição na súmula 593. A súmula teve como finalidade garantir a segurança 
jurídica aos cidadãos, tendo em vista que, mesmo após os tribunais superiores adotarem posicionamento pacífico sobre o tema, os tribunais estaduais julgavam ora considerando a vulnerabilidade como absoluta, ora como relativa.

Buscou-se demonstrar a existência de uma lacuna jurídica em relação ao ato infracional análogo ao crime de estupro de vulnerável, onde foi possível observar que a súmula e os demais julgados relativos ao tema em sua maioria analisam somente os crimes, considerando a relação entre o adulto e o menor de quatorze anos, e que poucos são os debates relativos à existência de relacionamento sexual consentido entre adolescentes.

A partir disso, abordou-se as particularidades relativas à criança e o adolescente. Inicialmente, foi explicado que os adolescentes também são punidos por sua conduta, na medida de sua responsabilidade, e que, em razão do seu estado de desenvolvimento, estas deveriam ser aplicadas somente nos casos mais necessários, respeitando-se os direitos previstos no ECA e na legislação penal.

Diante disso, defendeu-se a aplicação da teoria de Romeu e Julieta, segundo a qual se admite a relativização da vulnerabilidade quando os participantes da relação tiverem uma diferença de idade igual ou inferior a cinco anos, ou pelo menos a criação de uma regra semelhante no Brasil. Assim, seria possível relativizar a conduta sexual consentida entre adolescentes, sem deixar de assegurar à proteção as crianças e aos adolescentes.

A partir dessas reflexões, evidencia-se a necessidade de um debate maior sobre o tema pelos operadores do direito, principalmente por aqueles que fazem e aplicam as leis, com o fim de se construir uma doutrina jurídica sólida capaz de trazer pacificação e justiça social. 


\section{LEGAL GAP RELATED TO THE INFRACTION ACT ANALOGOUS TO THE CRIME OF RAPE OF VULNERABLE AND THE POSSIBI- LITY OF RELATIVIZATION OF THE VICTIM'S VULNERABILITY}

\section{ABSTRACT}

The present work analyzes the adequability of the legal, doctrinal and jurisprudence understandings related to victim's vulnerability in cases of infraction act analogous to the crime of rape of vulnerable when the sexual act is committed between adolescents with consent. For this purpose, it was used the qualitive method, considering that this is an exploratory study done through a deep bibliographical research. It could be verified that there is a legal gap related to the infraction act analogous to the crime of rape of vulnerable, which requires of the operators of the Law a specific analysis of cases involving consenting sexual intercourse among adolescents. As a solution to the legal gap, it is advocated that should be adopted in Brazil a similar clause to the exception of Romeu and Juliet, used in some states of the United States of America to descriminalize the sexual relationship among adolescents when the age difference between them is equal to or less than five years.

Keywords: Rape of vulnerable. Infraction act. Vulnerability. Legal gap. Romeu and Juliet law.

\section{REFERÊNCIAS}

ALEIXO, Klelia Canabrava. Problematizações sobre o estupro de vulnerável em face do princípio da proteção integral. Boletim IBCCRIM, pp. 08-09, 20/04/2009. Disponível em: <https://www.ibccrim.org.br/boletim_artigos/246-209-Abril-2010>. Acesso em: 09 jan. 2018.

AMIN, Andréa Rodrigues. Doutrina da proteção integral. In: MACIEL, Katia Regina F. L. A. (coord.), Curso de direito da criança e do adolescente: aspectos teóricos e práticos. São Paulo: Saraiva, 2014, pg. 52-57. 
ARANTES, Esther Maria de Magalhães. Proteção integral à criança e ao adolescente: proteção versus autonomia?. Psicol. clin., Rio de Janeiro , v. 21, n. 2, p. 431-450, 2009 . Disponível em: <http://www.scielo.br/scielo. php?script=sci_arttext\&pid=S0103-56652009000200012\&lng=en \&nrm=iso $>$. Access em: 11 fev. 2018.

BARROS, Francisco Dirceu. A natureza jurídica da vulnerabilidade nos novos delitos sexuais. Revista Jus Navigandi. Disponível em: < https://jus. com.br/artigos/17215>. Acesso em: 6 de jan. 2018.

BITENCOURT. Cezar Roberto. Tratado de direito penal 4: parte especial: dos crimes contra a dignidade sexual até os crimes contra a fé pública. $6^{a}$ ed. São Paulo: Saraiva, 2012. Não paginado.

BRASIL. Decreto-Lei no 2.848, de 7 de dezembro de 1940. Código Penal. Rio de Janeiro, 1940. Disponível em: <http://www.planalto.gov.br/ccivil_03/ decreto-lei/Del2848compilado.htm>. Acesso em: 15 dez. 2017.

Constituição da República Federativa do Brasil de 1988. Brasília, 1988. Disponível em: <http://www.planalto.gov.br/ccivil_03/constituicao/ constituicaocompilado.htm>. Acesso em: 15 de jan. 2018.

Lei n. 8.072 de 25 de julho de 1990. Dispõe sobre os crimes hediondos. Brasília, 1990. Disponível em: < http://www.planalto.gov.br/ ccivil_03/Leis/L8072.htm>. Acesso em: 15 dez. 2017.

Lei $n^{\circ}$ 8.069, de 13 de julho de 1990. Dispõe sobre o Estatuto da Criança e do Adolescente e dá outras providências. Brasília, 1990. Disponível em: < http://www.planalto.gov.br/Ccivil_03/leis/L8069.htm>. Acesso em: 25 nov. 2017.

CAPEZ, Fernando. Curso de direito penal Vol. 03. São Paulo: Saraiva, 2012. CORREA, Felipe Martins. ESTUPRO DE VULNERÁVEL BILATERAL, ADEQUAÇÃO SOCIAL E A “ROMEO AND JULIET LAW". Monografia. Unesc. Criciúma, 2016. Disponível em: <http://repositorio.unesc.net/handle/1/5072>. Acesso em: 25 nov. 2017.

D’ELIA. Fábio Suardi. Tutela penal da dignidade sexual e vulnerabilidade. Dissertação (Mestrando em direito). Pontifícia Universidade Católica de São Paulo. São Paulo, 2012. Disponível em: < https://sapientia.pucsp.br/handle/ handle/6011 >. Acesso em: 20 dez. 2018.

FERRAJOLI, Luigi. Direito e razão: teoria do garantismo penal. São 
Paulo: RT, 2012.

FULLER, Paulo. H.; DEZEM, Guilherme. M.; JUNIOR, Flávio. M. Estatuto da Criança e do Adolescente. São Paulo: Revista dos Tribunais, 2012.

GRECO, Rogério. Curso de Direito Penal- Parte especial Vol. III. $12^{\mathrm{a}}$ ed. Niterói, Rio de Janeiro: Impetus, 2015.

MORAES, Bianca Mota de; RAMOS, Helane Vieira. A prática do ato infracional. In: MACIEL, Katia Regina F. L. A. (coord.), Curso de direito da criança e do adolescente: aspectos teóricos e práticos. São Paulo: Saraiva, 2014, pg. 972-1090.

NUCCI, Guilherme de Souza. O crime de estupro sob o prisma da Lei 12.015/2009. Guilherme Nucci, 2014. Disponível em: < http://www. guilhermenucci.com.br/artigo/o-crime-de-estupro-sob-o-prisma-da-lei-12-0152009>. Acesso em 03 jan. 2018.

PINHEIRO, Rodrigo Paladino. A súmula como ferramenta facilitadora do Direito. Âmbito Jurídico, 2007. Disponível em: <http://www.ambito-juridico. com.br/site/index.php?n_link=revista_artigos_leitura\&artigo_id=2374 >. Acesso em: 11 jan. 2018.

SILVA, Andréia Antunes da. Uma abordagem jurídica e social do ato infracional análogo ao crime de estupro de vulnerável. Dissertação em Direito - Univali, Itajaí, 2014. Disponível em: < http://siaibib01.univali. br/pdf/Andreia\%20Antunes\%20da\%20Silva.pdf>. Acesso em: 20 dez. 2017. SOUZA, Sergio Augusto G. P. Os Direitos da Criança e os Direitos Humanos. Porto Alegre: Fabris, 2001.

SPOSATO, Karina Batista. Direito penal de adolescentes: elementos para uma teoria garantista. São Paulo: Saraiva, 2013.

STEINMETZ, Wilson; SEGER, Juliano dos Santos. Direito à autodeterminação sexual e princípio do melhor interesse da criança: a relativização da presunção de violência em crimes sexuais contra menores de quatorze anos. Revista de Direitos Fundamentais \& Democracia, Curitiba, volume 18, número 18, pg. 275-291, jul./dez. 2015. Disponível em: < http:// revistaeletronicardfd.unibrasil.com.br/index.php/rdfd/article/view/661>. Acesso em: 15 jan. 2018.

Coletânea temática de jurisprudência: direito penal e processual penal. Supremo Tribunal Federal, 2017. Disponível em: <http://www.stf.jus. 
br/arquivo/cms/publicacaoPublicacaoTematica/anexo/CTJ_Direito_Penal. pdf>. Acesso em: 5 jan. 2018.

Súmula 593, TERCEIRA SEÇÃO, julgado em 25/10/2017, DJe 06/11/2017. Disponível em: <http://www.stj.jus.br/SCON/sumanot/toc. jsp?materia=\%27DIREITO\%20PENAL\%27.mat>. Acesso em: 07 jan. 2018. STRECK, Lenio Luis. Súmulas no Direito Brasileiro: Eficácia, Poder e Função. Porto Alegre: Livraria do Advogado, 1998.

TAVORA, Nestor; ALENCAR, Rosmar Rodrigues. Curso de Direito Processual Penal. Salvador: JusPodvim, 2014. 